\title{
Synchronous Malignancy- A Rare Presentation of Double Primary in Female Genital Tract
}

\author{
Nanditha Srinivasan¹, Jovita Martin², Archana ${ }^{3}$, Sai Shalini, Lakshmi Narasimhan5, Manickavasagam
}

${ }^{1}$ Sri Ramachandra Medical College and Research Institute, Chennai, Tamilnadu, India. ${ }^{2}$ Department of Medical Oncology, Sri Ramachandra Medical College and Research Institute, Chennai, Tamilnadu, India. ${ }^{3}$ Department of Pathology, Sri Ramachandra Medical College and Research Institute, Chennai, Tamilnadu, India. ${ }^{4}$ Department of Pathology, Sri Ramachandra Medical College and Research Institute, Chennai, Tamilnadu, India. ${ }^{5}$ Department of Medical Oncology, Sri Ramachandra Medical College and Research Institute, Chennai, Tamilnadu, India. ${ }^{6}$ Department of Medical Oncology, Sri Ramachandra Medical College and Research Institute, Chennai, Tamilnadu, India.

\section{PRESENTATION OF CASE}

Adenocarcinomas of the cervix and borderline tumours of the ovary are very rare, rendering their synchrony to be even rarer. We present a case of a 25 -year-old unmarried, premenopausal woman with the chief complaints of lower abdominal pain, menorrhagia and discharge per vaginum for a duration of 1 month. Patient on clinical examination had abdominal distension and vague mass in the right hypochondrial region. On per vaginal examination, patient had swollen indurated anterior and posterior cervix.

\section{CLINICAL DIAGNOSIS}

Ca Cervix with a Mass Per Abdomen for Evaluation

\section{DIFFERENTIAL DIAGNOSIS}

Germ Cell Tumour Ovary, Endometrial Tumour Involving Cervix, Ca Cervix with an Ovarian Mass

\section{PATHOLOGICAL DISCUSSION}

The initial biopsy from the cervix was reported as adenoma malignum. Adenoma malignum was referred to as referred to as minimal deviation carcinoma / minimal deviation adenocarcinoma, is considered a rare variant of cervical carcinoma. After the complete staging procedure was done the diagnosis changed to be Adenocarcinoma endocervix with borderline ovarian cancer. Adenocarcinoma of the cervix is a malignant tumour of the cervix, the lowermost part of the uterus. It starts in the gland cells that produce mucus, proliferating in a glandular patterned usually metastasing to the lungs (5-35\%), bones (16\%) and (3\%).[1] There are various risk factors play a role in the etiology of these gynaecological malignancies such as nulliparity, menopause, infections like HPV, oestrogen hormone replacement therapy and exposure to carcinogens (Environmental or occupational). But no risk factors except nulliparity were found in this patient.
Corresponding Author:

Dr. Jovita Martin,

Department of Medical Oncology,

Sri Ramachandra Medical College and

Research Institute, Chennai,

Tamilnadu, India.

E-mail: jonimartin4@gmail.com

DOI: $10.14260 / \mathrm{jemds} / 2019 / 844$

Financial or Other Competing Interests: None.

How to Cite This Article:

Srinivasan A, Martin J, Archana. Synchronous malignancy- a rare presentation of double primary in female genital tract. J. Evolution Med. Dent. Sci. 2019;8(51):3896-3898, $10.14260 /$ jemds/2019/844

Submission 31-06-2019, Peer Review 15-11-2019, Acceptance 22-11-2019, Published 23-12-2019. 

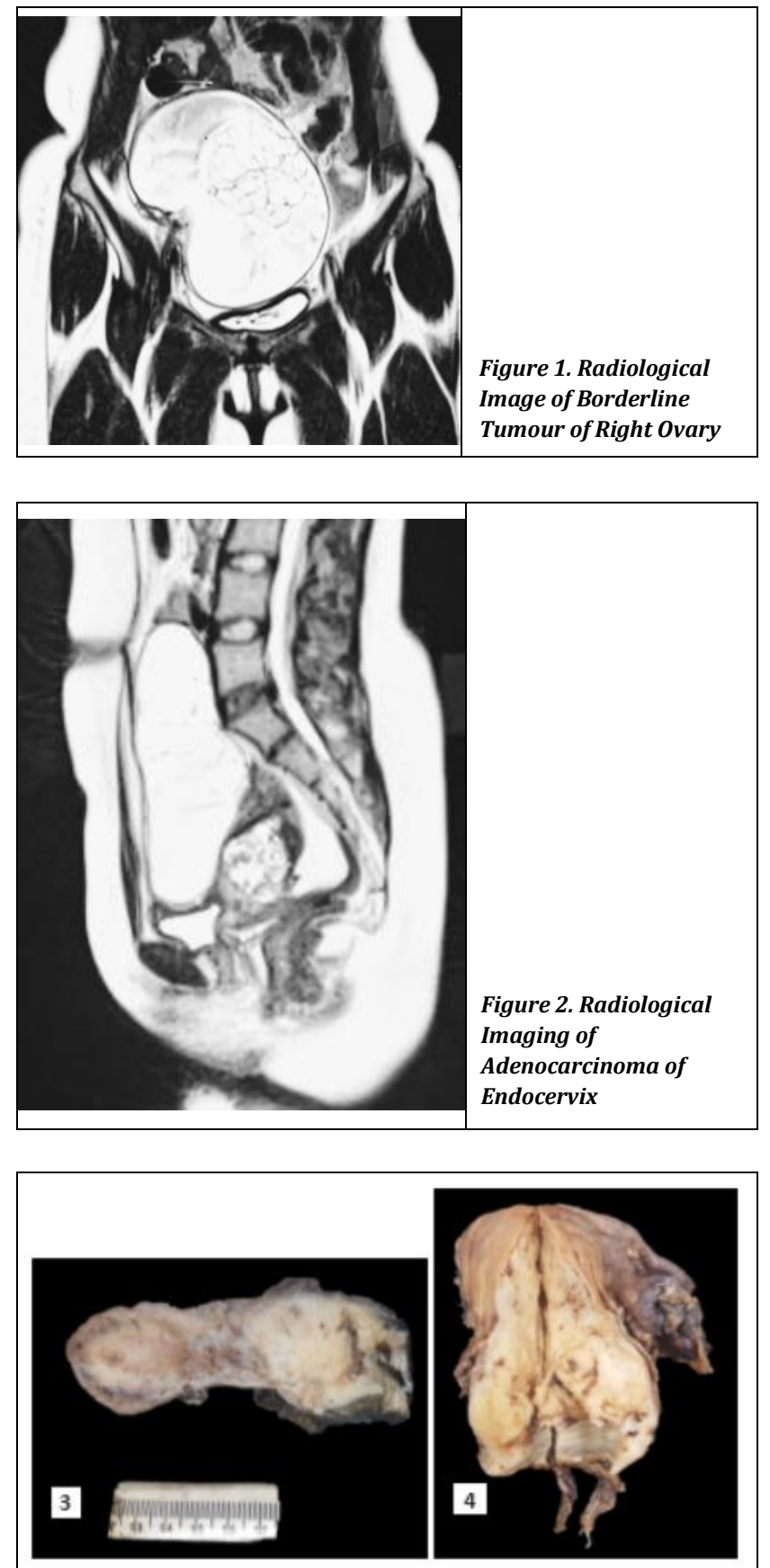

Figure. 3, 4. Gross Specimen- Gross Image of Uterus with Cervix and Vaginal Cuff Showing a Grey-White Firm Lesion in the Cervix Entering into the Endometrium

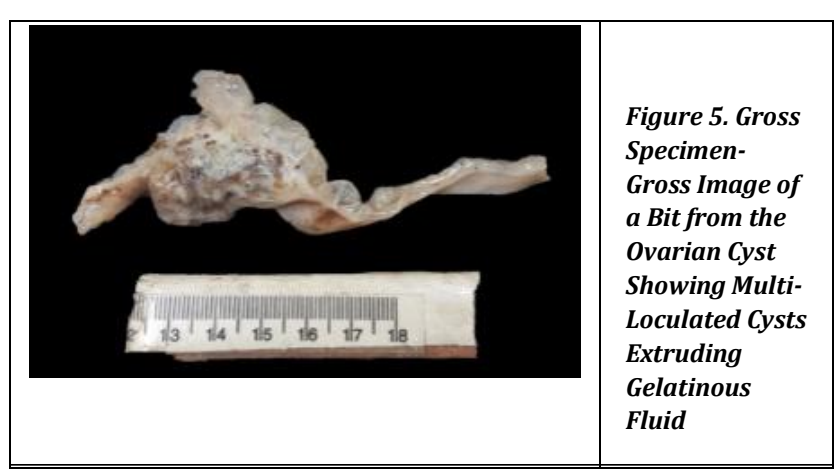

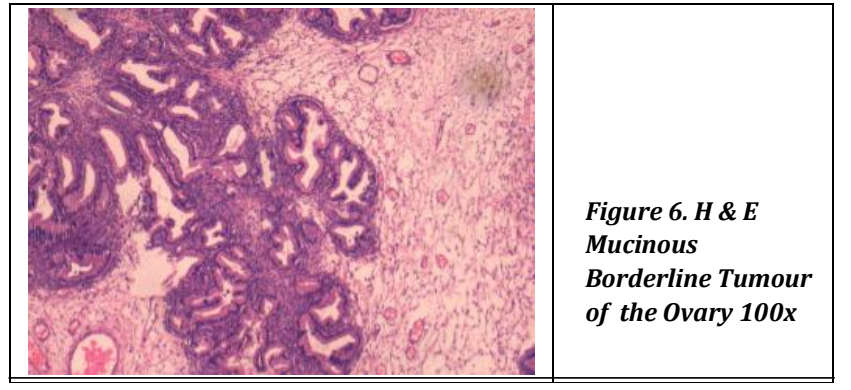
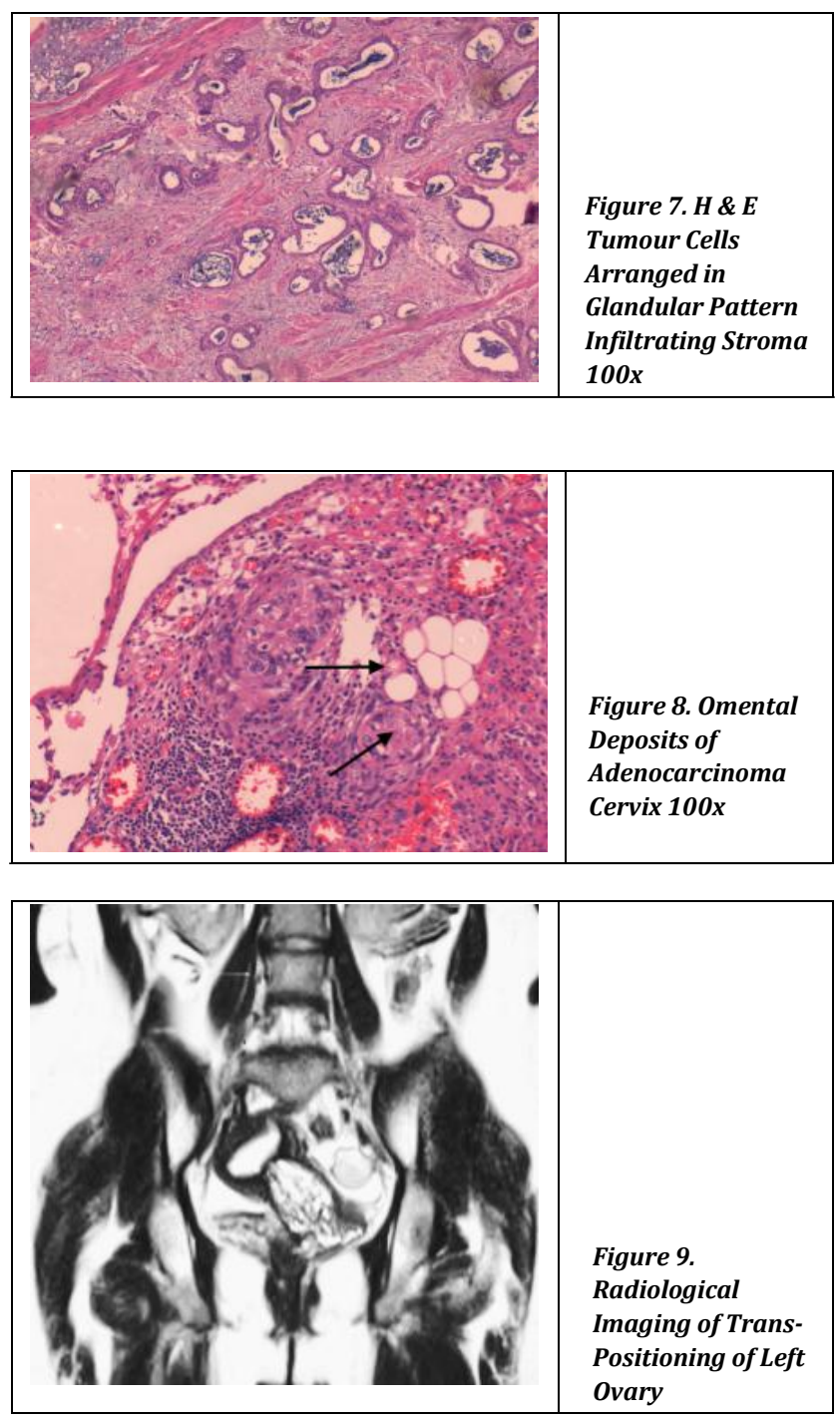

Mucinous borderline tumour is an atypical low metastaticpotential tumour that forms in the tissue covering the ovary. The cells are arranged in the form of multi-loculated cysts extruding gelatinous fluid, showing stratification on histopathological examination. They are of three types- BOT's with intraepithelial carcinoma; micro-invasive mucinous BOT's or both.[2] The mucinous tumours of the ovary are heterogeneous, and one tumour can show areas with benign, borderline and malignant features usually involve surface and superficial cortex, due to which proper sampling is required to rule out malignancy.[2,3] 


\section{DISCUSSION OF MANAGEMENT}

Management includes diagnosis and the treatment given. USG abdomen showed moderate ascites, Cervix appears bulky with predominantly hyperechoic lesion $4.9 \times 4.5 \mathrm{cms}$. Left ovary 4.7 x $3 \times 3.2 \mathrm{~cm}$ volume $24 \mathrm{cc}$. A thin walled cyst $17.2 \times 7.7 \mathrm{~cm}$ extending from umbilicus to epigastrium. Thick multiple septations were seen within. MR Abdomen showed large complex multiloculated right sided adnexal cystic lesion likely ovarian size 15.3 x 15.3 × $3.2 \mathrm{~cm}$. Complex lesion involving cervix extending to lower uterus and upper vagina size $5.7 \mathrm{x}$ $4.3 \times 4.2 \mathrm{~cm}$, fundal intramural fibroid $2.7 \times 2.1 \mathrm{~cm}$. Uterus size $4.5 \times 4.3 \times 5.8 \mathrm{~cm}$. Hemorrhage within the left ovarian size $4 \times$ $2.8 \mathrm{~cm}$ dominant follicle $2.3 \times 2 \mathrm{~cm}$. Right hydronephrosis, bilateral mild pleural effusion. [Fig. 1, 2]. Chest x-ray was normal. Serological investigations showed Anti Mullerian Hormone $3.8 \mathrm{ng} / \mathrm{ml}, \mathrm{CA}-125 \quad 74.1 \mathrm{U} / \mathrm{ml}$ and alkaline phosphatase and normal levels of beta HCG, CA-19.9. The patient was evaluated and treated in the surgical oncology department and underwent laparotomy and left ovary transpositioning [Fig. 9]. The post-operative histopathology specimens showed adenocarcinoma of endocervix involving the lower uterine segment, with myometrium and perimetrium spared; and a borderline tumour of right ovary and omental and para-aortic deposits [Fig 3-5, 6-8]. After surgery, the patient has completed 6 cycles of chemotherapy with paclitaxel and carboplatin and 50 Gy in 25 Fractions of pelvic radiation therapy.

\section{FINAL DIAGNOSIS}

The post-operative histopathology specimens showed adenocarcinoma of endocervix involving the lower uterine segment, with myometrium and perimetrium spared; and a borderline tumour of right ovary and omental and para-aortic deposits [Fig 3-5, 6-8]. There are no cases reported in the literature with the occurrence of both adenocarcinomas of the cervix and borderline tumors of the ovary together. In this case the adenocarcinoma of cervix was metastatic to omental nodules and paraaortic lymph nodes were positive hence the intention of treatment was palliative. The patient is on follow up last 6 months. Such rare occurrences reported in the literature might help us to have more experience in managing such rare synchronous malignancies. ${ }^{[4-11]}$

\section{REFERENCES}

[1] Gallup D. The spread and staging of cervical cancer. Glob Lib Women's Med 2008.

[2] Fischerova D, Zikan M, Dundr P, et al. Diagnosis, treatment and folow-up of borderline ovarian tumours. The Oncologist 2012;17(12):1515-33.

[3] Singh N. Synchronous tumours of female genital tract. Histopathology 2010;56(3):277-85.

[4] Szymańska-Dubowik A, Śniadecki M, Bianek-Bodzak A, et al. Mucinous borderline ovarian tumor: a case report with diagnostic insights on ultrasound findings. J Ultrason 2016;16(67):411-6.

[5] Shulan LV, Xue X, Sui Y, et al. Synchronous primary malignant neoplasms of the cervix and endometrium. Mol Clin Oncol 2017;6(5):661-4

[6] Katke RD, Gadekar S, Pagare P. A rare case of carcinoma of ovary with carcinoma of cervix. Journal of Case Reports 2014;4(1):217-20.

[7] Fatima Q, Dubey S, Kapuriya S. Synchronous primary carcinomas of cervix and ovary: a case report. IOSR Journal of Dental and Medical Sciences 2016;15(8):71-5.

[8] Herrinton LJ, Voigt LF, et al. Risk factors of synchronous primary endometrial and ovarian cancers. Ann Epidemiol 2001;11(8):529-33.

[9] Tiwari A, Jain A, Vashisth R, et al. Synchronous primary malignancy of ovary and cervix- the rare co-passengers. Indian J Gynecol Oncolog 2017;15:6.

[10] Srivastava KR, Zahra F. Synchronous primary malignancy of ovary and cervix with different histopathology: a rare presentation. The Internet Journal of Gynecology and Obstetrics 2009;12(2):1-4. 